\title{
Inversion of Wind-Stress Drag Coefficient in Simulating Storm Surges by Means of Regularization Technique
}

\author{
Junli Xu ${ }^{1}$, Yuhong Zhang ${ }^{2}$, Xianqing $\mathrm{Lv}^{3}$ and Qiang Liu ${ }^{2, *}$ \\ 1 School of Mathematics and Physics, Qingdao University of Science and Technology, Qingdao 266100, China; \\ xjlshy1983@163.com \\ 2 College of Engineering, Ocean University of China, Qingdao 266100, China; yuhong3551@126.com \\ 3 Key Laboratory of Physical Oceanography (Ocean University of China), Ministry of Education, Ocean \\ University of China, Qingdao 266100, China; xqinglv@ouc.edu.cn \\ * Correspondence: liuqiang@ouc.edu.cn; Tel.: +86-13583215966
}

Received: 31 July 2019; Accepted: 23 September 2019; Published: 25 September 2019

\begin{abstract}
In this study, water levels observed at tide stations in the Bohai Sea, Yellow Sea, and East China Sea during Typhoons 7203 and 8509 were assimilated into a numerical assimilation storm surge model combined with regularization technique to study the wind-stress drag coefficient. The Tikhonov regularization technique with different regularization parameters was tested during the assimilation. Using the regularization technique, the storm surge elevations were successfully simulated in the whole sea areas during Typhoons 7203 and 8509. The storm surge elevations calculated with the regularization technique and the elevations calculated with independent point method were separately compared with the observed data. Comparison results demonstrated that the former was closer to the observed data. The regularization technique had the best performance when the regularization parameter was 100. The spatial distribution of the inverted drag coefficient, storm surge elevations, and the wind fields during both typhoons were presented. Simulated results indicated that the change of drag coefficient is more significant in the coastal regions of the Bohai Sea and north of the Yellow Sea. Further analysis showed that the rising water elevation in the Bohai Sea is mostly attributed to the influence of onshore winds, and the negative storm surge in the South Yellow Sea is mainly caused by offshore winds.
\end{abstract}

Keywords: storm surge; adjoint assimilation; regularization technique; typhoon; drag coefficient

\section{Introduction}

Abnormal sea level rise or fall associated with storm surge usually results from strong winds and atmospheric perturbations [1-4]. The storm surge generated by the typhoon originating from the northwestern Pacific Ocean can result in large scale flooding and destruction on the shore of the Bohai Sea, Yellow Sea, and East China Sea. Storm surge and related coastal flooding can bring about not only damage to properties but also loss of lives [5-9], and the abnormal low water level threatens the maritime safety and coastal facility [10-12].

Typhoons can give rise to serious storm surges in the coastal areas. To improve the storm surge forecast, some researchers have studied storm surges in some regions using different methods in recent years. Lionello et al. utilized the variational data assimilation method to forecast the storm surge in the north of Adriatic Sea, showing that the assimilation method can effectively improve the reliability of the storm surge forecast [13]. Peng and Xie combined a linear model with adjoint model of Princeton Ocean Model to present a four-dimensional variational assimilation method [14]. On the basis of this adjoint optimal technique, Peng et al. adjusted the surface boundary and initial conditions in the Princeton 
Ocean Model, and suggested that it was better to simultaneously adjust those two conditions in the process of data assimilation due to uncertainty of error [15]. Using a coupled model between storm surge and wave, five storm surges from typhoon were simulated in the East China Sea [16]. Results showed that waves should be considered in predicting storm surges. Fan et al. utilized the adjoint assimilation method to optimize the drag coefficient at independent points, and obtained the spatially varying drag coefficient in the Bohai Sea, Yellow Sea, and East China Sea [17]. To improve storm surge forecast, Li et al. optimized the drag coefficient and initial condition using the three-dimensional numerical and adjoint ocean model, and their result demonstrated that simultaneously adjusting both of them can achieve much more improvements [18]. Feng et al. studied the possible influence of future climate changes on storm surges along the Qingdao coast. Results showed that sea level rise mainly influenced the water level during storm surges, while the sea surface temperature affected the intensity of the surges [19]. Xu et al. investigated the impacts of tide-surge interactions on storm surges in the coast of the Bohai Sea, Yellow Sea, and East China Sea using a two-dimensional coupled tide-surge model. It indicated that the tide-surge interactions should be considered when predicting storm surge levels [20].

Nevertheless, the ill-posed problem of solution often appears in the process of adjoint assimilation. In order to solve this problem, regularization technique is introduced [21]. The Tikhonov regularization technique is commonly used, and also proves to be effective in many practical problems [22,23].

For the storm surge forecast, accurate wind data are important in storm surge forecasts. Winds from numerical weather models are often found to be weaker than observations [24]. The variations of wind field to a large extent affect the sea water level. Meanwhile, the drag coefficient is also an important factor in the process of simulating the storm surge. Therefore, in the present study, by assimilating water levels observed at tide stations during Typhoons 7203 and 8509 into a storm surge model, we will optimize the drag coefficient in the Bohai Sea, Yellow Sea, and East China Sea using the Tikhonov regularization technique with different regularization parameters, and examine the spatially varying drag coefficient in these areas. Furthermore, the storm surge elevations simulated with the Tikhonov regularization technique and the elevations calculated with independent point method [17] are separately compared with the observed data. The spatially varying wind stress drag coefficient with wind speed is obtained by the regularization method, thus providing the service for the accurate simulation and prediction of storm surges.

\section{Materials and Methods}

\subsection{Numerical Adjoint Model}

The numerical adjoint model includes two parts: the forward model and adjoint model. The former is a depth averaged two-dimensional storm surge model governed by the depth averaged continuity equation and momentum equations [17].

$$
\begin{gathered}
\frac{\partial \zeta}{\partial t}+\frac{\partial[(h+\zeta) u]}{\partial x}+\frac{\partial[(h+\zeta) v]}{\partial y}=0 \\
\frac{\partial u}{\partial t}+u \frac{\partial u}{\partial x}+v \frac{\partial u}{\partial y}-f v+\frac{k u \sqrt{u^{2}+v^{2}}}{h+\zeta}-A\left(\frac{\partial^{2} u}{\partial x^{2}}+\frac{\partial^{2} u}{\partial y^{2}}\right)+g \frac{\partial \zeta}{\partial x}+\frac{1}{\rho_{w}} \frac{\partial P_{a}}{\partial x}-\frac{\rho_{a}}{\rho_{w}} \frac{C_{d} W_{x} \sqrt{W_{x}^{2}+W_{y}^{2}}}{h+\zeta}=0 \\
\frac{\partial v}{\partial t}+u \frac{\partial v}{\partial x}+v \frac{\partial v}{\partial y}+f u+\frac{k v \sqrt{u^{2}+v^{2}}}{h+\zeta}-A\left(\frac{\partial^{2} v}{\partial x^{2}}+\frac{\partial^{2} v}{\partial y^{2}}\right)+g \frac{\partial \zeta}{\partial y}+\frac{1}{\rho_{w}} \frac{\partial P_{a}}{\partial y}-\frac{\rho_{a}}{\rho_{w}} \frac{C_{d} W_{y} \sqrt{W_{x}^{2}+W_{y}^{2}}}{h+\zeta}=0
\end{gathered}
$$

where $t$ is time, $x$ and $y$ are separately the Cartesian coordinates pointing to the east and north, $h$ is unperturbed water depth, $\zeta$ is sea surface level, with respective to the unperturbed depth, $h+\zeta$ is total depth of water, $u$ and $v$ are separately the current speeds towards the east and north, $f=2 \Omega \sin \phi$ is the Coriolis parameter ( $\Omega$ is earth spinning angular velocity, and $\phi$ is north latitude), $k$ is bottom friction factor, $A$ is eddy viscosity coefficient in the horizontal direction, $g$ is gravitational acceleration. 
Seawater density $\rho_{w}$ is $1025 \mathrm{~kg} / \mathrm{m}^{3}$, and air density $\rho_{a}$ is $1.27 \mathrm{~kg} / \mathrm{m}^{3} . C_{d}$ is wind-stress drag coefficient, $\left(W_{x}, W_{y}\right)$ is surface wind field and $P_{a}$ is air pressure on the sea surface.

In the present study, the wind field of Jelesnianski [25] was used for the tropical typhoon and is expressed as follows:

$$
\vec{W}=\left\{\begin{array}{cc}
\frac{r}{R+r}\left(V_{o x} \vec{i}+V_{o y} \vec{j}\right)+W_{R} \frac{1}{r}\left(\frac{r}{R}\right)^{\frac{3}{2}}(A \vec{i}+B \vec{j}), \quad 0<r \leq R \\
\frac{R}{R+r}\left(V_{o x} \vec{i}+V_{o y} \vec{j}\right)+W_{R} \frac{1}{r}\left(\frac{R}{r}\right)^{\frac{1}{2}}(A \vec{i}+B \vec{j}), \quad r>R
\end{array},\right.
$$

where the unit vectors $\vec{i}$ and $\vec{j}$ point to the east and north, respectively, $V_{o x}$ and $V_{o y}$ are the travelling velocities of storm center, $r$ is the distance of the grid center from the storm center, $R$ is radius of the maximum wind speed $W_{R}$

$$
\begin{gathered}
A=-\left[\left(x-x_{c}\right) \sin \theta+\left(y-y_{c}\right) \cos \theta\right], \\
B=\left[\left(x-x_{c}\right) \cos \theta-\left(y-y_{c}\right) \sin \theta\right],
\end{gathered}
$$

where the coordinate $(x, y)$ is the grid center, $\left(x_{c}, y_{c}\right)$ is the storm center; $\theta$ is the inflow angle, as the following

$$
\theta= \begin{cases}20^{\circ}, & r \leq R \\ 15^{\circ}, & r>R\end{cases}
$$

The pressure field of tropical cyclone is originated from Jelesnianski [25]:

$$
P_{a}=\left\{\begin{array}{cc}
P_{0}+\frac{1}{4}\left(P_{\infty}-P_{0}\right)\left(\frac{r}{R}\right)^{3}, & r \leq R \\
P_{\infty}-\frac{3}{4}\left(P_{\infty}-P_{0}\right)\left(\frac{R}{r}\right), & r>R
\end{array},\right.
$$

where the pressure $P_{a}$ is at $r$ on the sea surface, pressure $P_{0}$ is at the cyclone center, $P_{\infty}$ is ambient pressure. Here $P_{\infty}$ fetches the value of $1020 \mathrm{hPa}$.

To build the adjoint equations, the cost function uses the following definition:

$$
J(\zeta)=\frac{1}{2} K_{\zeta} \int_{\Sigma}(\zeta-\hat{\zeta})^{2} d x d y d t
$$

where $\zeta$ is the simulation, $\hat{\zeta}$ is the observation, $K_{\zeta}$ is a constant. Then, the Lagrangian function is defined as follows:

$$
\begin{gathered}
L=J(\zeta)+\int_{\Sigma} \zeta_{a}\left\{\frac{\partial \zeta}{\partial t}+\frac{\partial[(h+\zeta) u]}{\partial x}+\frac{\partial[(h+\zeta) v]}{\partial y}\right\} d x d y d t \\
+\int_{\Sigma} u_{a}\left[\frac{k u \sqrt{u^{2}+v^{2}}}{h+\zeta}-A\left(\frac{\partial^{2} u}{\partial x^{2}}+\frac{\partial^{2} u}{\partial y^{2}}\right)+\frac{1}{\rho} \frac{\partial p_{a}}{\partial x}-\frac{\rho_{a}}{\rho} \frac{C_{d} W_{x} \sqrt{W_{x}{ }^{2}+W_{y^{2}}}}{h+\zeta}\right] d x d y d t \\
+\int_{\Sigma} v_{a}\left[\frac{k v \sqrt{u^{2}+v^{2}}}{h+\zeta}-A\left(\frac{\partial^{2} v}{\partial x^{2}}+\frac{\partial^{2} v}{\partial y^{2}}\right)+\frac{1}{\rho} \frac{\partial p_{a}}{\partial y}-\frac{\rho_{a}}{\rho} \frac{C_{d} W_{y} \sqrt{W_{x}{ }^{2}+W_{y}{ }^{2}}}{h+\zeta}\right] d x d y d t .
\end{gathered}
$$

Analogous to the means of He et al. [26], we can obtain the adjoint equations:

$$
\begin{gathered}
\frac{\partial \zeta_{a}}{\partial t}+u \frac{\partial \zeta_{a}}{\partial x}+v \frac{\partial \zeta_{a}}{\partial y}+\frac{k u \sqrt{u^{2}+v^{2}} u_{a}}{(h+\zeta)^{2}}+\frac{k v \sqrt{u^{2}+v^{2}} v_{a}}{(h+\zeta)^{2}}+g \frac{\partial u_{a}}{\partial x}+g \frac{\partial v_{a}}{\partial y}=K_{\zeta}(\zeta-\hat{\zeta}) \\
\frac{\partial u_{a}}{\partial t}-\left[f+\frac{k u v}{(h+\zeta) \sqrt{u^{2}+v^{2}}}\right] v_{a}-u_{a} \frac{\partial u}{\partial x}-v_{a} \frac{\partial v}{\partial x}+\frac{\partial}{\partial x}\left(u u_{a}\right) \\
+\frac{\partial}{\partial y}\left(v u_{a}\right)+(h+\zeta) \frac{\partial \zeta_{a}}{\partial x}+A\left(\frac{\partial^{2} u_{a}}{\partial x^{2}}+\frac{\partial^{2} u_{a}}{\partial y^{2}}\right)-\frac{k\left(2 u^{2}+v^{2}\right) u_{a}}{(h+\zeta) \sqrt{u^{2}+v^{2}}}=0 \\
\frac{\partial v_{a}}{\partial t}-\left[f+\frac{k u v}{(h+\zeta) \sqrt{u^{2}+v^{2}}}\right] u_{a}-u_{a} \frac{\partial u}{\partial y}-v_{a} \frac{\partial v}{\partial y}+\frac{\partial}{\partial x}\left(u v_{a}\right) \\
+\frac{\partial}{\partial y}\left(v v_{a}\right)+(h+\zeta) \frac{\partial \zeta a}{\partial y}+A\left(\frac{\partial^{2} v_{a}}{\partial x^{2}}+\frac{\partial^{2} v_{a}}{\partial y^{2}}\right)-\frac{k\left(u^{2}+2 v^{2}\right) v_{a}}{(h+\zeta) \sqrt{u^{2}+v^{2}}}=0
\end{gathered}
$$


where $\zeta_{a}, u_{a}, v_{a}$ are separately the adjoint variables of $\zeta, u$, and $v$.

\subsection{Regularization Technique}

The regularization technique is usually used to solve the ill-posed inverse problem. The Tikhonov regularization technique [21] is widely used, and its major idea is presented blow.

The Tikhonov functional is structured as follows:

$$
f=J+J_{\text {sta }}
$$

where the cost function $J$ is given by Equation (9), $J_{\text {sta }}=\frac{\alpha}{2}\left\|b-b_{0}\right\|^{2}$ is the "stabilizing functional" in the Tikhonov regularization technique, $\alpha(\alpha>0)$ is a regularization parameter, $b_{0}$ and $b$ are separately the prior and optimized control variables in the model. The control variable gradient of the Tikhonov functional is:

$$
f_{b}=d+\alpha\left(b-b_{0}\right)
$$

and the Hessian matrix of the functional is

$$
f_{b b}=D+\alpha I
$$

where $d$ is the first derivative of the function $J, D$ is the second derivative, $I$ is the identity matrix.

It is very important for the implementation of the regularization technique to choose an appropriate parameter $\alpha$, that is, calculate $\alpha$ to minimize the Tikhonov functional. Engl's criterion is a feasible solution for determination of the parameter $\alpha$.

Suppose that $p=b-b_{0}$, then in a neighborhood of $b_{0}$,

$$
f(p) \approx s(p)=J\left(b_{0}\right)+d\left(b_{0}\right) p+\frac{1}{2} p^{\mathrm{T}} D\left(b_{0}\right) p+\frac{\alpha}{2}\|p\|^{2} .
$$

Setting $\frac{d s}{d p}=0$, we obtain:

$$
\left(D_{0}+\alpha I\right) p+d_{0}=0 .
$$

According to Equation (16), we obtain the following formulas:

$$
\begin{gathered}
b=b_{0}-\left(D_{0}+\alpha I\right)^{-1} d_{0}, \\
\frac{d b}{d \alpha}=\frac{d p}{d \alpha}=-\left(D_{0}+\alpha I\right)^{-1} p, \\
\frac{d^{2} b}{d \alpha^{2}}=\frac{d^{2} p}{d \alpha^{2}}=2\left(D_{0}+\alpha I\right)^{-1}\left(D_{0}+\alpha I\right)^{-1} p .
\end{gathered}
$$

According to Engl's criterion, we need to minimize the functional:

$$
\phi(\alpha)=\frac{J}{\alpha}, \alpha>0 .
$$

To that end, we need to solve the following equation:

$$
\phi^{\prime}(\alpha)=\frac{\alpha J^{\prime}-J}{\alpha^{2}}=0, \alpha>0 .
$$

Then we obtain $\alpha J^{\prime}-J=0$. Suppose that $F(\alpha)=\alpha J^{\prime}-J$ and by applying the Newton iteration method, we can obtain:

$$
\alpha_{1}=\alpha_{0}-\frac{F\left(\alpha_{0}\right)}{F^{\prime}\left(\alpha_{0}\right)},
$$


where $\alpha$ can be constantly updated. According to Equation (15), we can get:

$$
J^{\prime}=J_{p} \frac{d p}{d \alpha}=-d\left(D_{0}+\alpha I\right)^{-1} p=\alpha p^{\mathrm{T}}\left(D_{0}+\alpha I\right)^{-1} p .
$$

Therefore, $F\left(\alpha_{0}\right)$ and $F^{\prime}\left(\alpha_{0}\right)$ can be calculated as follows:

$$
\begin{gathered}
F(\alpha)=\alpha^{2} p^{\mathrm{T}}\left(D_{0}+\alpha I\right)^{-1} p-J, \\
F^{\prime}(\alpha)=\alpha J^{\prime \prime}+J^{\prime}-J^{\prime}=\alpha J^{\prime \prime}=\alpha\left[p^{\mathrm{T}}\left(D_{0}+\alpha I\right)^{-1} p-3 \alpha p^{\mathrm{T}}\left(D_{0}+\alpha I\right)^{-1}\left(D_{0}+\alpha I\right)^{-1} p\right] .
\end{gathered}
$$

As we can see from Equations (22)-(25), we need to calculate the Hessian matrix to determine the parameter $\alpha$. However, the calculation of the Hessian matrix is usually very difficult. For simplicity, the regularization parameter $\alpha$ in Equation (12) can be regarded as a constant.

\subsection{Numerical Experiment}

The areas studied in this paper include the Bohai Sea, Yellow Sea, and East China Sea. The specific scope of longitude is between $117.5^{\circ} \mathrm{E}$ and $130.5^{\circ} \mathrm{E}$ and the latitude is between $24.5^{\circ} \mathrm{N}$ and $41^{\circ} \mathrm{N}$. At the initial time, sea surface level and current velocity were treated as 0 in the model. The background $\mathrm{Cd}$ in the area is 0.0026 , which is in the range $0.002-0.004$ as estimated from ocean observations [27]. The bottom drag coefficient was set to a constant (0.0016) in the whole sea area. Taiwan Strait and the first island chains were set as the open boundaries. It is supposed that no water flows into or away from the seacoast along the closed boundaries which means that the normal current component is 0 . In the finite difference scheme, water elevation is at the grid center and the current speed is on the edge of grid, that is, Arakawa $\mathrm{C}$ is adopted. Bathymetry data was obtained from the First Institute of Oceanography, State Oceanic Administration. The horizontal resolution is $5^{\prime} \times 5^{\prime}$. The time increment is $60 \mathrm{~s}$. The model is driven by the surface stress Equation (4) and pressure Equation (8). In present study, Typhoons 7203 (from July 25 to 28, 1972) and 8509 (from August 17 to 20, 1985) were chosen for simulation. The trajectories of the two Typhoons are shown in Figure 1. Observation data from 10 tide stations was used for assimilation, and their locations are also shown in Figure 1. In order to obtain the temporally varying wind-stress drag coefficient, the typhoon process separates into a few periods, and each period lasts $6 \mathrm{~h}$. Track data of typhoons used in the study are from the website “http://www.typhoon.org.cn/".

The observation data used for assimilation were water levels, observed at tide stations during Typhoons 7203 and 8509. To implement the Tikhonov regulation technique, the Tikhonov function as Equation (7) is used. Different regularization parameters $(0,1,10,100$, and 1000) were tested to evaluate the effect of the regularization parameter on the simulated results. Accordingly, five numerical experiments, denoted by Cases $0-4$, were carried out. Then, the simulated storm surge elevations were compared with the observations. Additionally, another experiment, denoted by Case 5, was performed with the independent point method [17], for comparison to further demonstrate the efficiency of the regularization technique. 


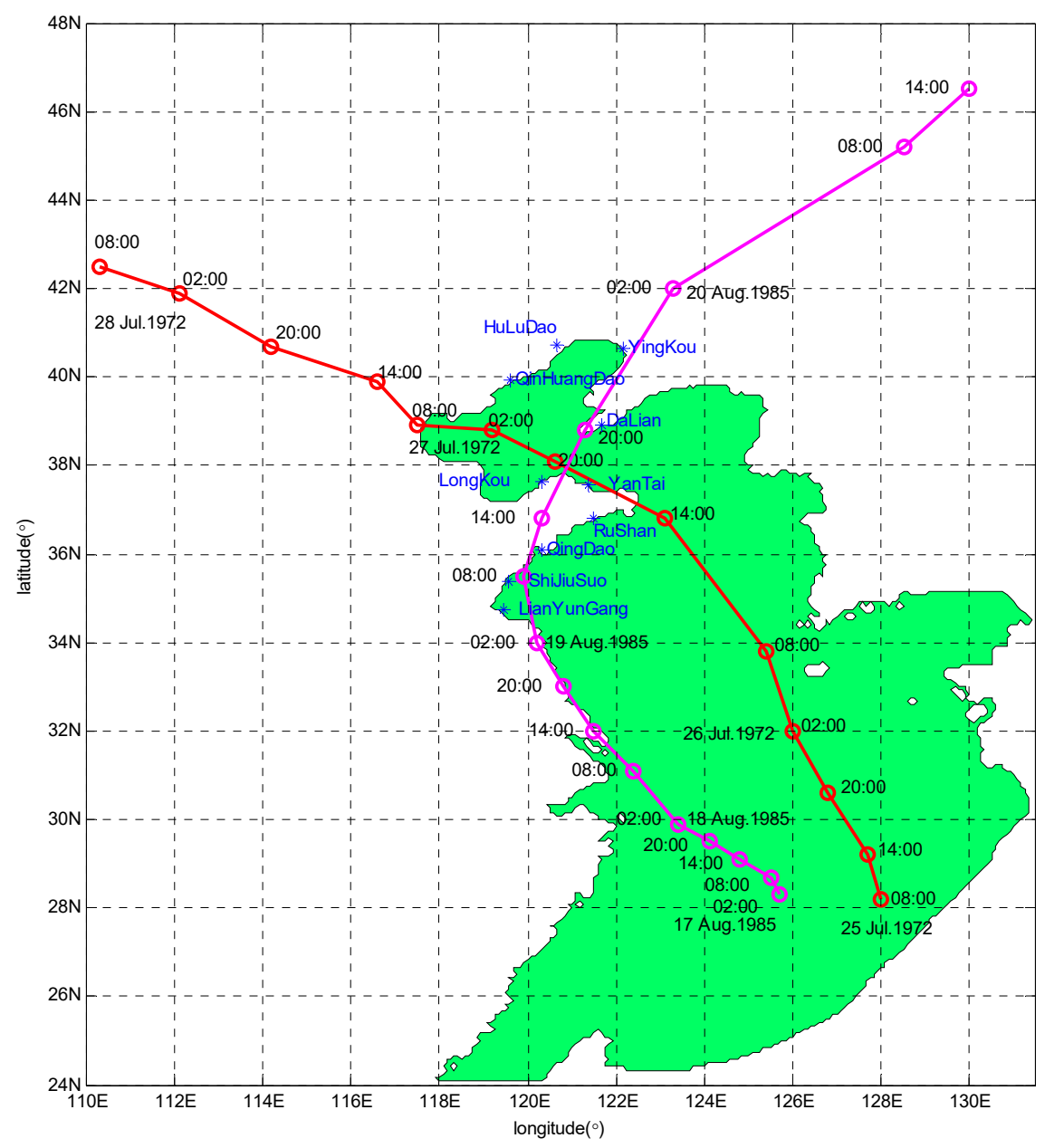

Figure 1. Tide stations and trajectories of Typhoons 7203 and 8509 . Blue asterisks denote the locations of tide stations. Red and mauve solid lines are the trajectories of Typhoons 7203 and 8509 respectively. Red and mauve circles indicate time.

\section{Results and Discussion}

\subsection{Comparison between Simulation and Observation of Storm Surge Levels}

In this section, a sequence of comparisons between the simulations of storm surge levels and observations are carried out at several tide stations during Typhoons 7203 and 8509, and the model results are further analyzed.

The root-mean-square (RMS) errors between simulation and observations are presented in Tables 1 and 2 for each period during Typhoons 7203 and 8509, respectively. The RMS errors at each tide station are listed in Table 3. In addition, the comparison of the peak surge and peak time between simulation and observations at tide stations during Typhoons 7203 and 8509 are also shown in Tables 4 and 5, respectively. Specially, the simulated and observed storm surge elevations, and their differences at DaLian, HuLuDao, QinHuangDao, and RuShan tide stations during Typhoon 7203 are plotted in Figures 2-5, respectively. The similar results at RuShan, ShiJiuSuo, and LianYunGang tide stations during Typhoon 8509 are shown in Figures 6-8, respectively.

In this study, the RMS errors between simulation and observation of storm surge levels, peak surge, and peak time during typhoons serve as criteria for determination of the best simulation. As we can see from Table 1, the mean RMS differences in C0-C5, for Typhoon 7203, are 15, 14, 14, 13, 16, and $20 \mathrm{~cm}$, respectively. Particularly, the mean value in C3 is the smallest. Mean RMS differences obtained by the regularization technique are smaller than that by the independent point method. For Typhoon 8509, as shown in Table 2, the mean RMS differences in C0-C4 are respectively 23, 19, 19, 19, 
and $19 \mathrm{~cm}$, and smaller than that in C5 (24 cm). As shown in Table 3, the mean RMS differences at all tide stations in C1-C4 are obviously smaller than those in C5 during Typhoons 7203 and 8509. From the Table 4 we can see that, at DaLian and HuLudao tide stations, both peak surge and peak time in C3 are the closest to the observation. In Case 3, the peak surge at QinHuangdao tide station is the closest to the observation and the peak time at RuShan tide station is the closest to the observation. In Table 5, the result of C3 at RuShan station is closer to the observation in terms of both the peak surge and peak time. At the LianYungang station, C4 is the best. In the C0, where the regularization technique is not employed, the simulation of the peak surge and peak time is poorer than that in C3 for Typhoon 7203, and the RMS errors are higher than those in C1-C4 for Typhoon 8509. These results demonstrate that, compared with the simulation with the independent point method, the simulation with the regularization technique is closer to observation. In addition, the results of Typhoon 7203 show that too large or too small regularization parameter may have a negative influence on performance of the method. Therefore, it is very important to choose an appropriate regularization parameter for the Tikhonov regularization technique. However, the choice of the regularization parameter has little impact on the simulation results of Typhoon 8509. These findings are consistent with the results shown in Figures 2-8.

Table 1. Mean square errors between simulation and observation of storm surge levels in each period during Typhoon 7203 (unit: cm).

\begin{tabular}{cccccccccccccc}
\hline Case & $\mathbf{1}$ & $\mathbf{2}$ & $\mathbf{3}$ & $\mathbf{4}$ & $\mathbf{5}$ & $\mathbf{6}$ & $\mathbf{7}$ & $\mathbf{8}$ & $\mathbf{9}$ & $\mathbf{1 0}$ & $\mathbf{1 1}$ & $\mathbf{1 2}$ & Mean \\
\hline $\mathrm{C} 0$ & 11 & 7 & 5 & 6 & 11 & 16 & 29 & 19 & 22 & 27 & 20 & 12 & 15 \\
$\mathrm{C} 1$ & 6 & 7 & 4 & 5 & 6 & 14 & 26 & 18 & 21 & 26 & 19 & 12 & 14 \\
$\mathrm{C} 2$ & 5 & 7 & 5 & 5 & 5 & 16 & 27 & 18 & 19 & 25 & 19 & 12 & 14 \\
C3 & 7 & 8 & 6 & 6 & 6 & 14 & 24 & 16 & 16 & 23 & 18 & 13 & 13 \\
C4 & 10 & 11 & 10 & 9 & 11 & 20 & 22 & 19 & 20 & 23 & 19 & 15 & 16 \\
C5 & 10 & 11 & 10 & 9 & 8 & 35 & 45 & 32 & 24 & 21 & 22 & 14 & 20 \\
\hline
\end{tabular}

Table 2. Mean square errors between simulation and observation of storm surge levels in each period during Typhoon 8509 (unit: cm).

\begin{tabular}{lccccccccccccccc}
\hline Case & $\mathbf{1}$ & $\mathbf{2}$ & $\mathbf{3}$ & $\mathbf{4}$ & $\mathbf{5}$ & $\mathbf{6}$ & $\mathbf{7}$ & $\mathbf{8}$ & $\mathbf{9}$ & $\mathbf{1 0}$ & $\mathbf{1 1}$ & $\mathbf{1 2}$ & $\mathbf{1 3}$ & $\mathbf{1 4}$ & Mean \\
\hline $\mathrm{C} 0$ & 11 & 8 & 4 & 7 & 10 & 20 & 11 & 15 & 39 & 23 & 31 & 74 & 32 & 37 & 23 \\
$\mathrm{C} 1$ & 11 & 7 & 4 & 7 & 10 & 9 & 7 & 10 & 7 & 21 & 32 & 66 & 36 & 43 & 19 \\
$\mathrm{C} 2$ & 11 & 7 & 4 & 7 & 10 & 9 & 7 & 10 & 7 & 21 & 31 & 66 & 35 & 42 & 19 \\
$\mathrm{C} 3$ & 11 & 8 & 4 & 7 & 10 & 10 & 8 & 9 & 7 & 19 & 29 & 67 & 34 & 40 & 19 \\
C4 & 13 & 11 & 6 & 8 & 12 & 11 & 10 & 8 & 8 & 18 & 27 & 69 & 32 & 39 & 19 \\
C5 & 13 & 7 & 5 & 9 & 10 & 9 & 7 & 11 & 11 & 35 & 49 & 101 & 38 & 30 & 24 \\
\hline
\end{tabular}

Table 3. Mean square errors between simulation and observation of storm surge levels at tide stations during Typhoons 7203 and 8509 (unit: cm).

\begin{tabular}{|c|c|c|c|c|c|c|c|c|c|c|c|c|}
\hline \multirow{2}{*}{ Tide Stations } & \multicolumn{6}{|c|}{7203} & \multicolumn{6}{|c|}{8509} \\
\hline & $\mathrm{CO}$ & $\mathrm{C} 1$ & $\mathrm{C} 2$ & $\mathrm{C} 3$ & $\mathrm{C} 4$ & C5 & $\mathrm{CO}$ & $\mathrm{C} 1$ & $\mathrm{C} 2$ & $\mathrm{C} 3$ & $\mathrm{C} 4$ & C5 \\
\hline DaLian & 13 & 13 & 12 & 13 & 19 & 25 & 56 & 50 & 50 & 50 & 52 & 73 \\
\hline YingKou & 13 & 11 & 11 & 12 & 14 & 19 & * & $*$ & * & $*$ & $*$ & * \\
\hline HuLuDao & 10 & 10 & 11 & 10 & 16 & 23 & * & * & $*$ & * & $*$ & * \\
\hline QinHuangDao & 11 & 10 & 10 & 9 & 11 & 27 & 27 & 31 & 31 & 29 & 27 & 27 \\
\hline LongKou & 19 & 17 & 18 & 16 & 19 & 23 & $*$ & $*$ & $*$ & $*$ & $*$ & $*$ \\
\hline YanTai & 26 & 26 & 26 & 22 & 26 & 27 & 22 & 24 & 23 & 22 & 21 & 23 \\
\hline RuShan & 9 & 7 & 7 & 7 & 10 & 25 & 10 & 11 & 11 & 11 & 11 & 19 \\
\hline QingDao & 16 & 15 & 15 & 15 & 14 & 19 & 14 & 14 & 13 & 13 & 12 & 20 \\
\hline ShiJiuSuo & 18 & 15 & 15 & 13 & 12 & 19 & 16 & 15 & 14 & 14 & 14 & 24 \\
\hline LianYunGang & 26 & 23 & 23 & 20 & 17 & 25 & 34 & 16 & 16 & 16 & 17 & 25 \\
\hline Mean & 16 & 15 & 15 & 14 & 16 & 23 & 26 & 23 & 23 & 22 & 22 & 30 \\
\hline
\end{tabular}


Table 4. The peak surge and peak time between simulation and observation of storm surge levels at four tide stations during Typhoon 7203.

\begin{tabular}{ccccccccc}
\hline Typhoon & \multicolumn{7}{c}{ 7203 } \\
$\begin{array}{c}\text { Tide } \\
\text { Stations }\end{array}$ & \multicolumn{2}{c}{ DaLian } & \multicolumn{2}{c}{ HuLuDao } & \multicolumn{2}{c}{ QinHuangDao } & RuShan \\
\hline & $\begin{array}{c}\text { Peak surge } \\
(\mathrm{cm})\end{array}$ & $\begin{array}{c}\text { Peak } \\
\text { time }(\mathrm{h})\end{array}$ & $\begin{array}{c}\text { Peak surge } \\
(\mathrm{cm})\end{array}$ & $\begin{array}{c}\text { Peak } \\
\text { time }(\mathrm{h})\end{array}$ & $\begin{array}{c}\text { Peak surge } \\
(\mathrm{cm})\end{array}$ & $\begin{array}{c}\text { Peak } \\
\text { time }(\mathrm{h})\end{array}$ & $\begin{array}{c}\text { Peak surge } \\
(\mathrm{cm})\end{array}$ & $\begin{array}{c}\text { Peak } \\
\text { time }(\mathrm{h})\end{array}$ \\
\hline C0 & 135 & 35.6 & 211 & 43.6 & 185 & 42 & 55 & 46.6 \\
C1 & 136 & 36.3 & 213 & 43.7 & 182 & 45.9 & 54 & 46.5 \\
C2 & 136 & 36.3 & 212 & 43.7 & 181 & 45.8 & 56 & 46.5 \\
C3 & 134 & 36.3 & 204 & 43.7 & 181 & 46.9 & 57 & 46.9 \\
C4 & 137 & 36.3 & 199 & 43.8 & 172 & 43.6 & 58 & 47.5 \\
C5 & 106 & 35.3 & 193 & 43.9 & 173 & 43.0 & 62 & 52.7 \\
Observation & 127 & 39 & 204 & 44 & 181 & 46 & 53 & 47 \\
\hline
\end{tabular}

Table 5. The peak surge and peak time between simulation and observation of storm surge levels at three tide stations during Typhoon 8509.

\begin{tabular}{|c|c|c|c|c|c|c|}
\hline \multirow{3}{*}{$\begin{array}{c}\text { Typhoon } \\
\text { Tide } \\
\text { Stations }\end{array}$} & \multicolumn{6}{|c|}{8509} \\
\hline & \multicolumn{2}{|c|}{ RuShan } & \multicolumn{2}{|c|}{ ShiJiusuo } & \multicolumn{2}{|c|}{ LianYungang } \\
\hline & Peak surge $(\mathrm{cm})$ & Peak time (h) & Peak surge $(\mathrm{cm})$ & Peak time (h) & Peak surge $(\mathrm{cm})$ & Peak time (h) \\
\hline $\mathrm{CO}$ & 91 & 55.2 & 92 & 50.6 & 196 & 49 \\
\hline $\mathrm{C} 1$ & 84 & 58.3 & 88 & 48.1 & 113 & 48 \\
\hline C2 & 85 & 58.3 & 88 & 48.1 & 113 & 48 \\
\hline C3 & 88 & 58.2 & 87 & 48.1 & 111 & 48 \\
\hline C4 & 84 & 58 & 86 & 48.1 & 109 & 48 \\
\hline C5 & 53 & 75 & 79 & 48.5 & 114 & 48.3 \\
\hline Observation & 92 & 58 & 89 & 49 & 95 & 48 \\
\hline
\end{tabular}
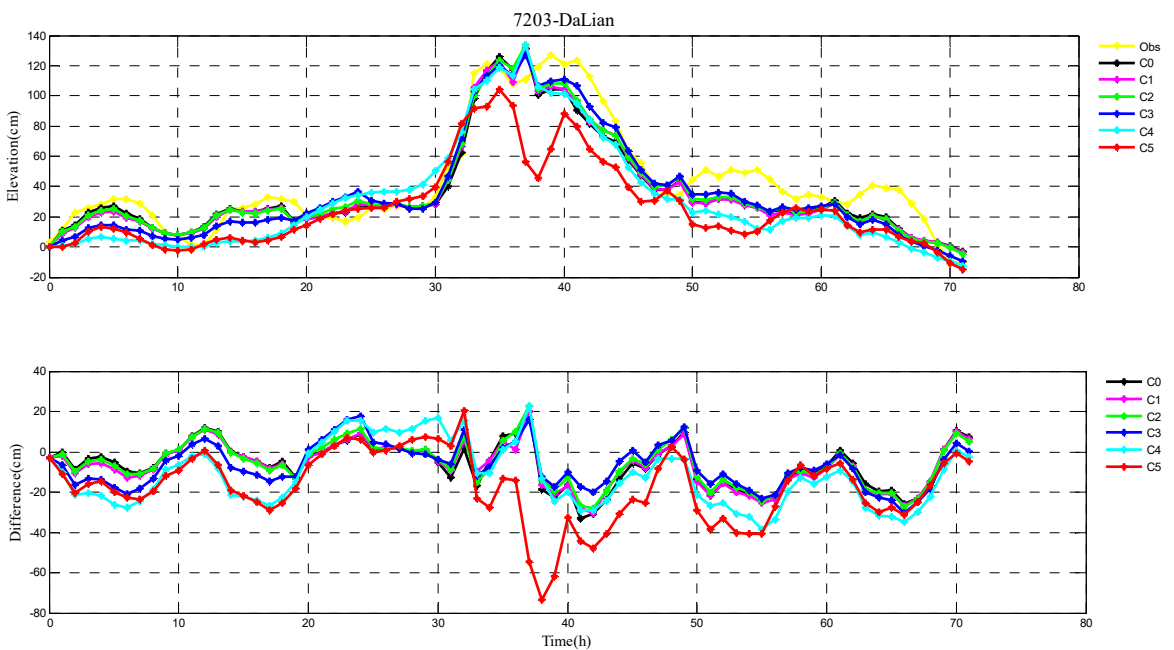

Figure 2. The storm surge elevations $(\mathrm{cm})$ in six cases $(\mathrm{C} 0, \mathrm{C} 1, \mathrm{C} 2, \mathrm{C} 3, \mathrm{C} 4, \mathrm{C} 5)$ and observations (yellow line) (top) and the differences between them (bottom) during Typhoon 7203 at DaLian tide station. 

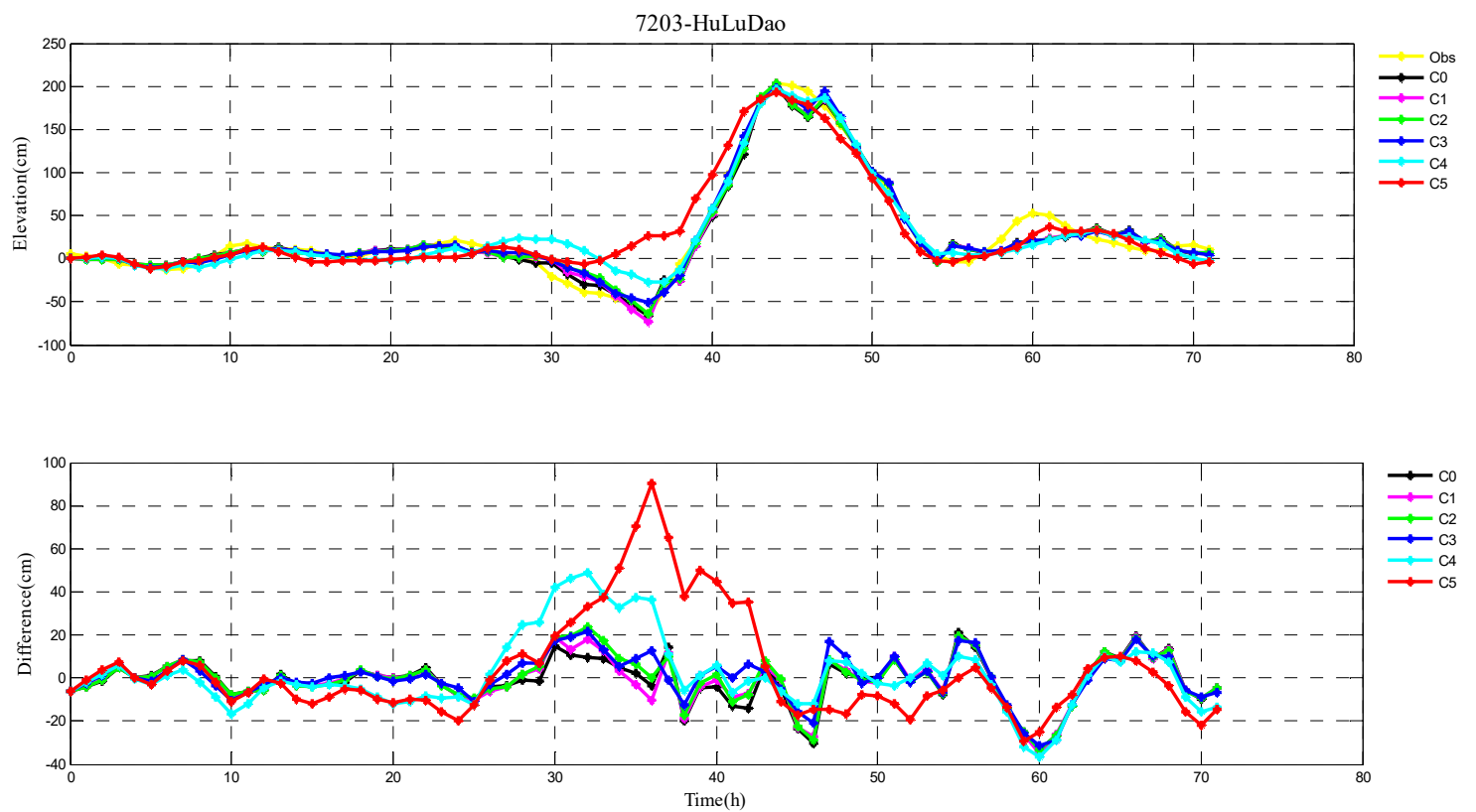

Figure 3. The storm surge elevations $(\mathrm{cm})$ in six cases $(\mathrm{C} 0, \mathrm{C} 1, \mathrm{C} 2, \mathrm{C} 3, \mathrm{C} 4, \mathrm{C} 5)$ and observations (yellow line) (top) and the differences between them (bottom) during Typhoon 7203 at HuLuDao tide station.
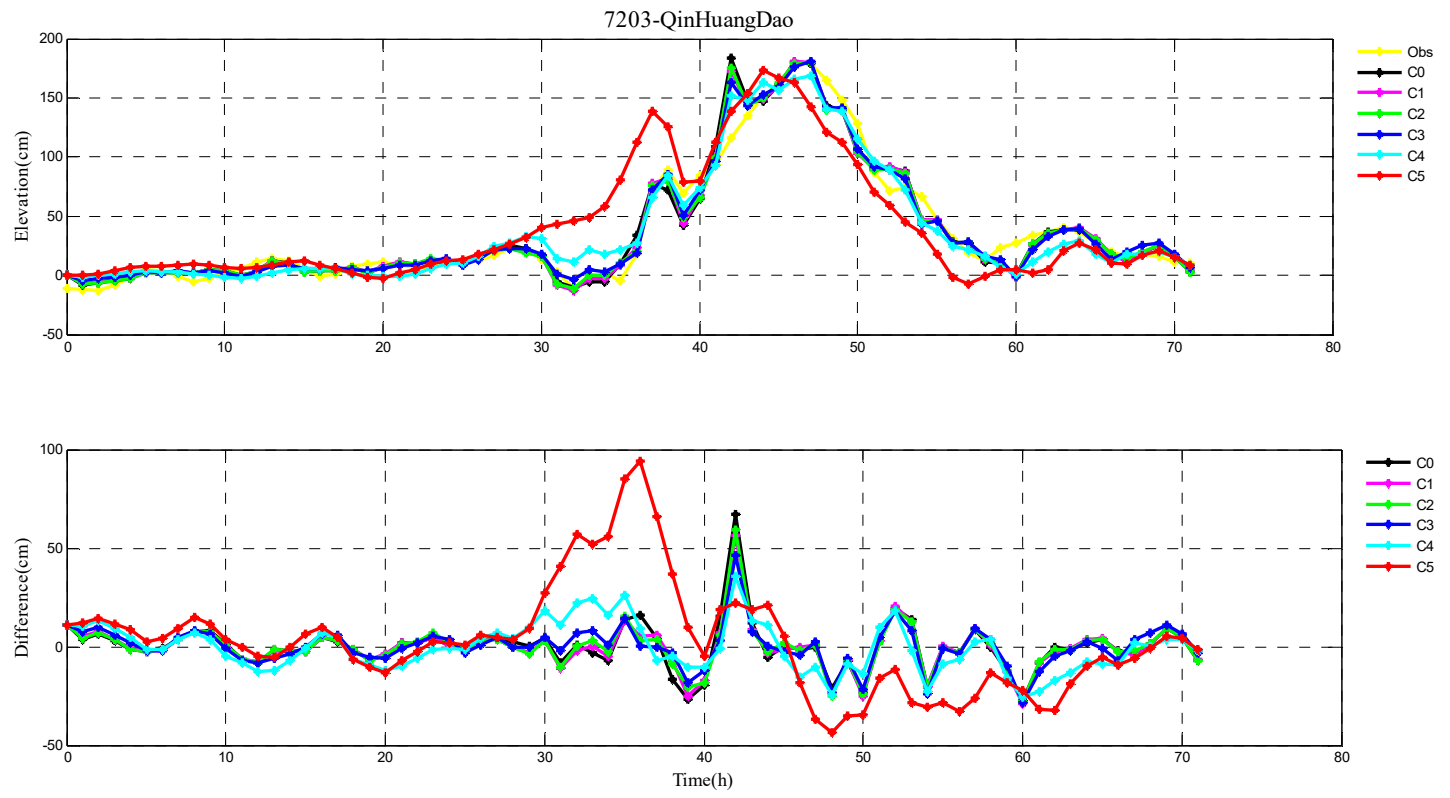

Figure 4. The storm surge elevations $(\mathrm{cm})$ in six cases $(\mathrm{C} 0, \mathrm{C} 1, \mathrm{C} 2, \mathrm{C} 3, \mathrm{C} 4, \mathrm{C} 5)$ and observations (yellow line) (top) and the differences between them (bottom) during Typhoon 7203 at QinHuangDao tide station. 

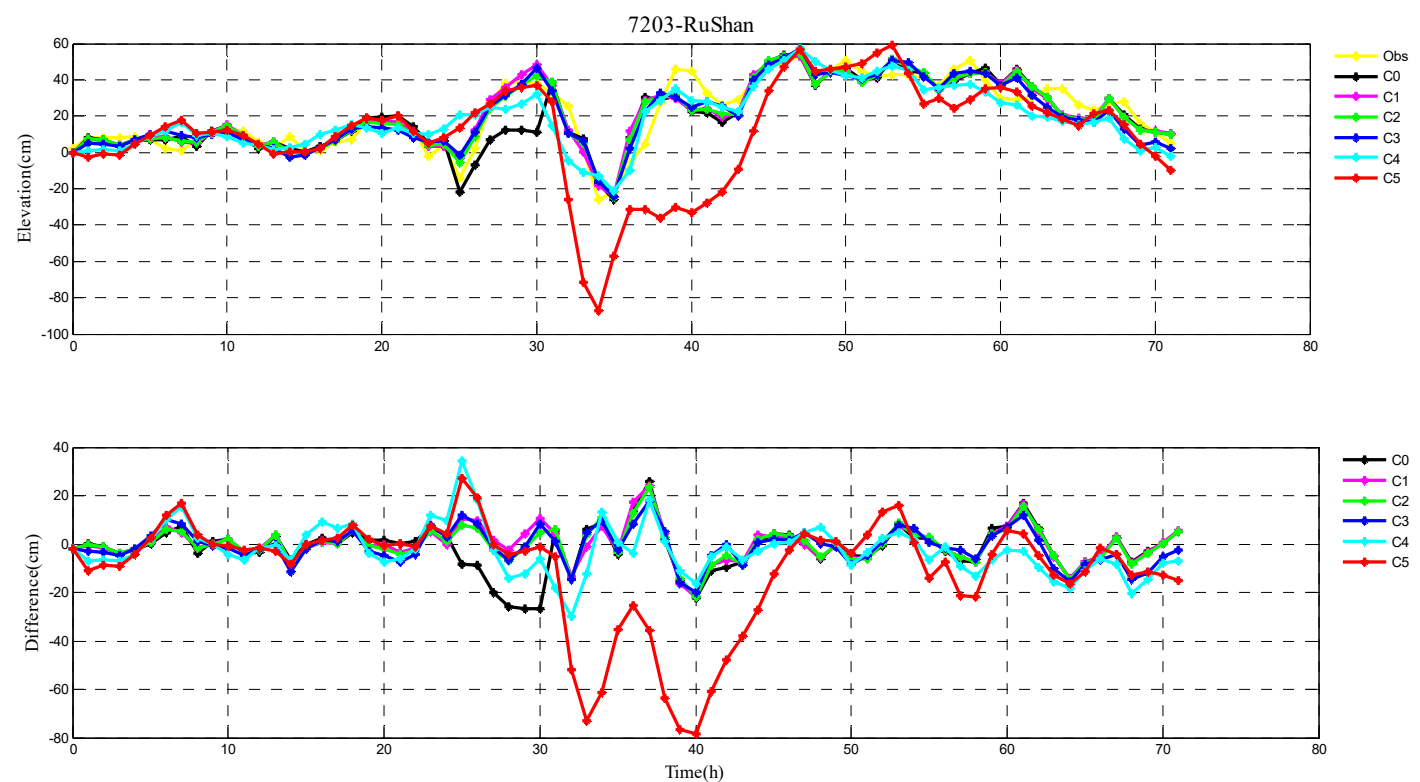

Figure 5. The storm surge elevations (cm) in six cases (C0, C1, C2, C3, C4, C5) and observations (yellow line) (top) and the differences between them (bottom) during Typhoon 7203 at RuShan tide station.
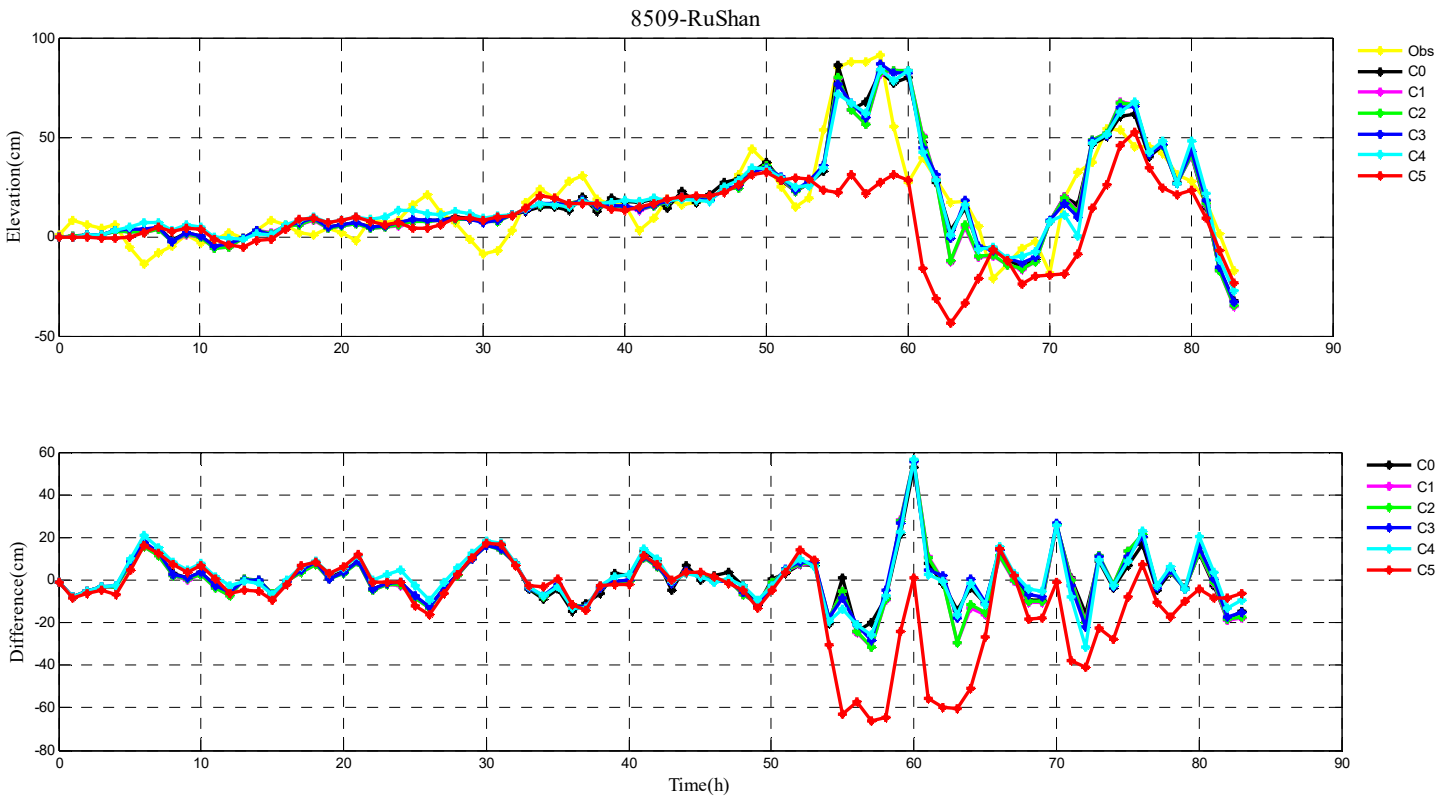

Figure 6. The storm surge elevations $(\mathrm{cm})$ in six cases $(\mathrm{C} 0, \mathrm{C} 1, \mathrm{C} 2, \mathrm{C} 3, \mathrm{C} 4, \mathrm{C} 5)$ and observations (yellow line) (top) and the differences between them (bottom) during Typhoon 8509 at RuShan tide station. 

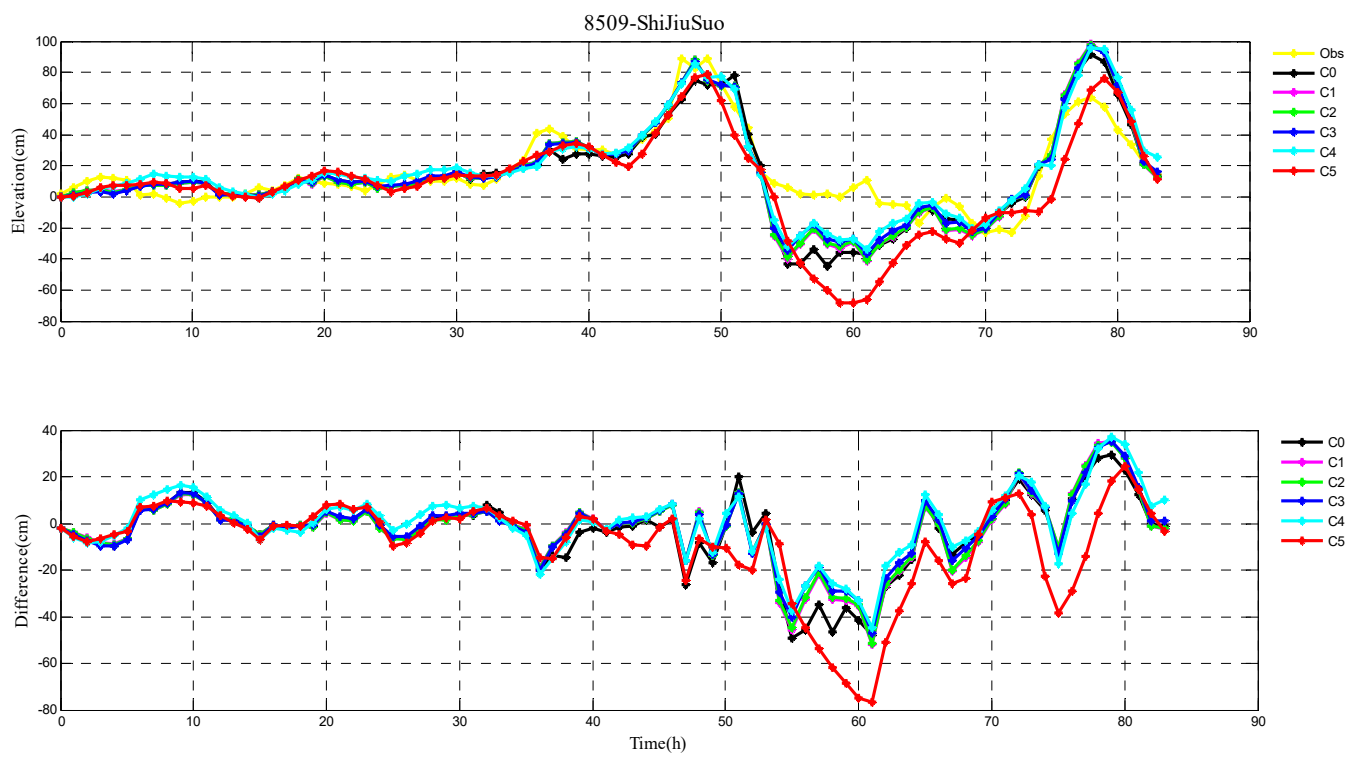

Figure 7. The storm surge elevations (cm) in six cases $(\mathrm{C} 0, \mathrm{C} 1, \mathrm{C} 2, \mathrm{C} 3, \mathrm{C} 4, \mathrm{C} 5)$ and observations (yellow line) (top) and the differences between them (bottom) during Typhoon 8509 at ShiJiuSuo tide station.
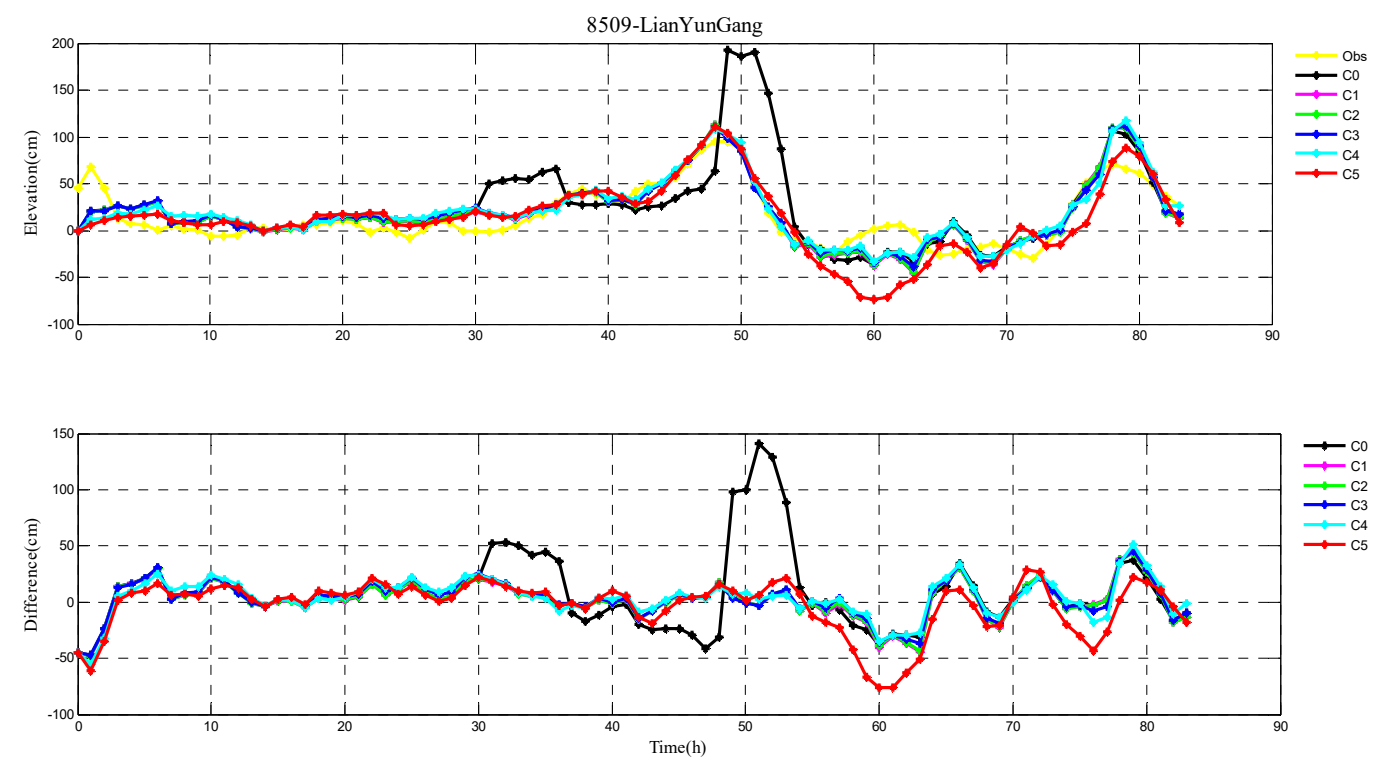

Figure 8. The storm surge elevations $(\mathrm{cm})$ in six cases $(\mathrm{C} 0, \mathrm{C} 1, \mathrm{C} 2, \mathrm{C} 3, \mathrm{C} 4, \mathrm{C} 5)$ and observations (yellow line) (top) and the differences between them (bottom) during Typhoon 8509 at LianYunGang tide station.

\subsection{Spatial Distribution of the Drag Coefficient}

After comparison in terms of the mean RMS difference, peak surge, and peak time, in this section we chose the result of Case 3 as an example to investigate the spatial distribution of the inverted drag coefficient and storm surge elevation.

Fan et al. [17] also inverted the spatial distributions of the drag coefficient during Typhoons 7203 and 8509 , but using the independent point method. In this study, in order to compare with the study of Fan et al. [17], the spatial distributions of the drag coefficient in the sixth and seventh periods (that is, the end of the sixth and seventh running periods) during Typhoon 7203 are shown in Figure 9a,b, and the spatial distributions of the drag coefficient in the seventh and ninth periods (that is, the end of the seventh and ninth running periods) during Typhoon 8509 are mapped in Figure 10a,b, respectively. From Figures $9 \mathrm{a}, \mathrm{b}$ and $10 \mathrm{a}, \mathrm{b}$, the drag coefficient calculated with the regularization technique show 
more variations than those in Figures $11 a, b$ and $12 a, b$. In addition, we can also find that the extrema of drag coefficients appear in the Bohai Sea and northern Yellow Sea, especially in the coastal areas, while values change slightly in the south of the Yellow Sea and nearly remains unchanged in the East China Sea. One possible interpretation for this is that the convergence and divergence of water are stronger in the shallower water areas and in the coastal areas.
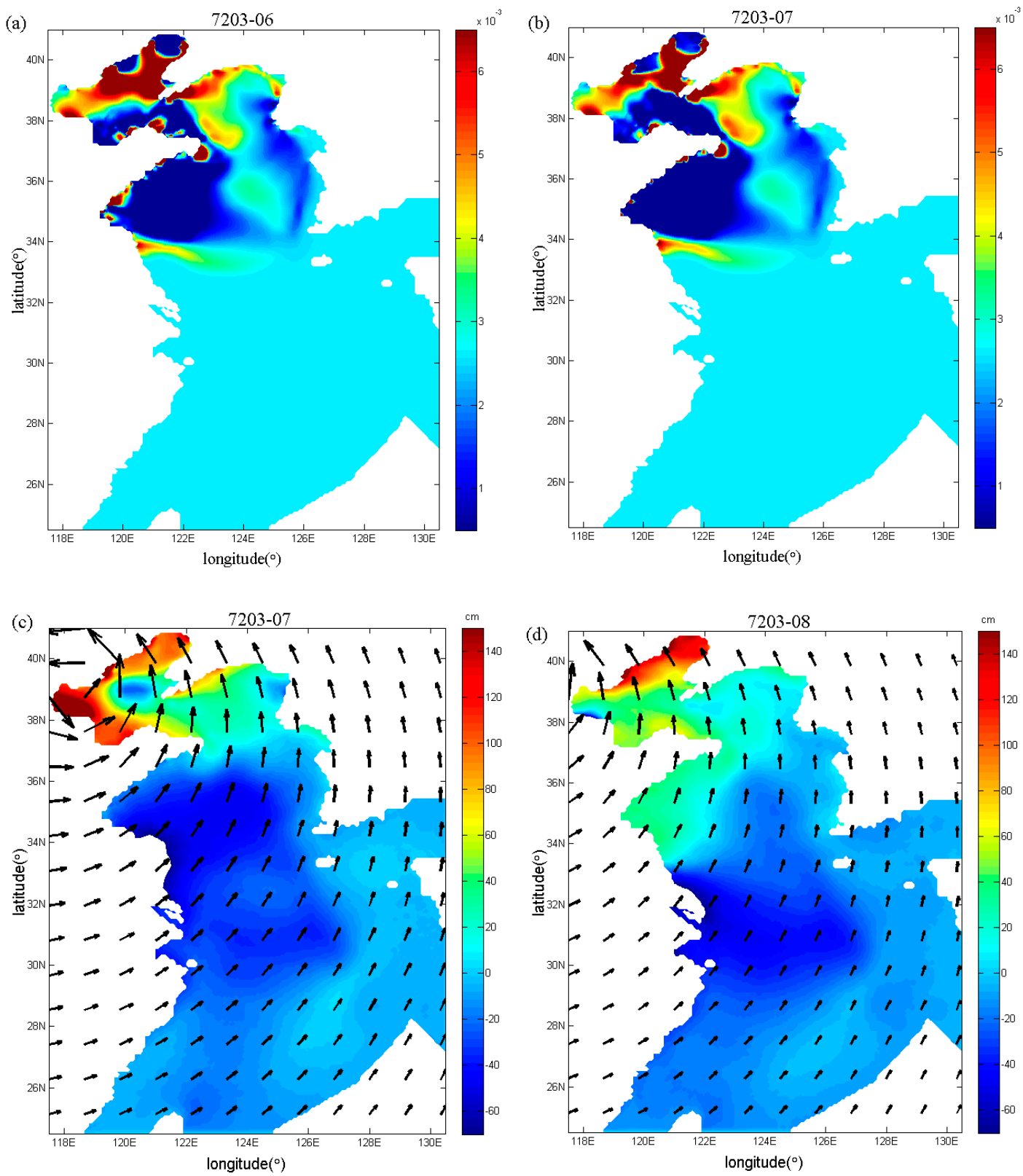

Figure 9. Spatial distributions $(\mathbf{a}, \mathbf{b})$ of the drag coefficient in the sixth and seventh periods and spatial distributions (c,d) of storm surge elevation and wind field in the seventh and eighth periods in Case 3 during Typhoon 7203. 

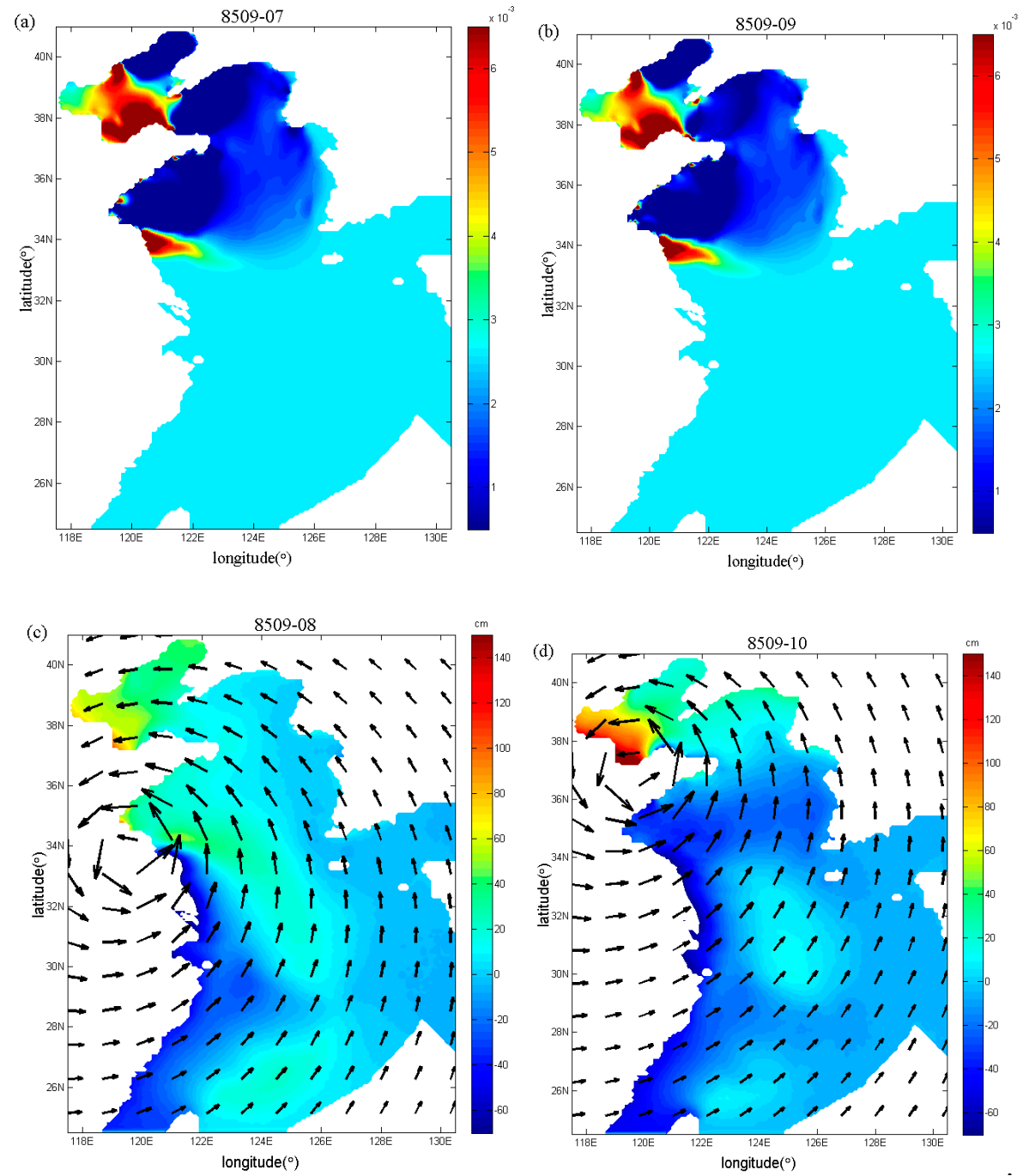

Figure 10. Spatial distributions $(\mathbf{a}, \mathbf{b})$ of the drag coefficient in the seventh and ninth periods and spatial distributions (c,d) of storm surge elevation and wind field in the eighth and tenth periods in Case 3 during Typhoon 8509.
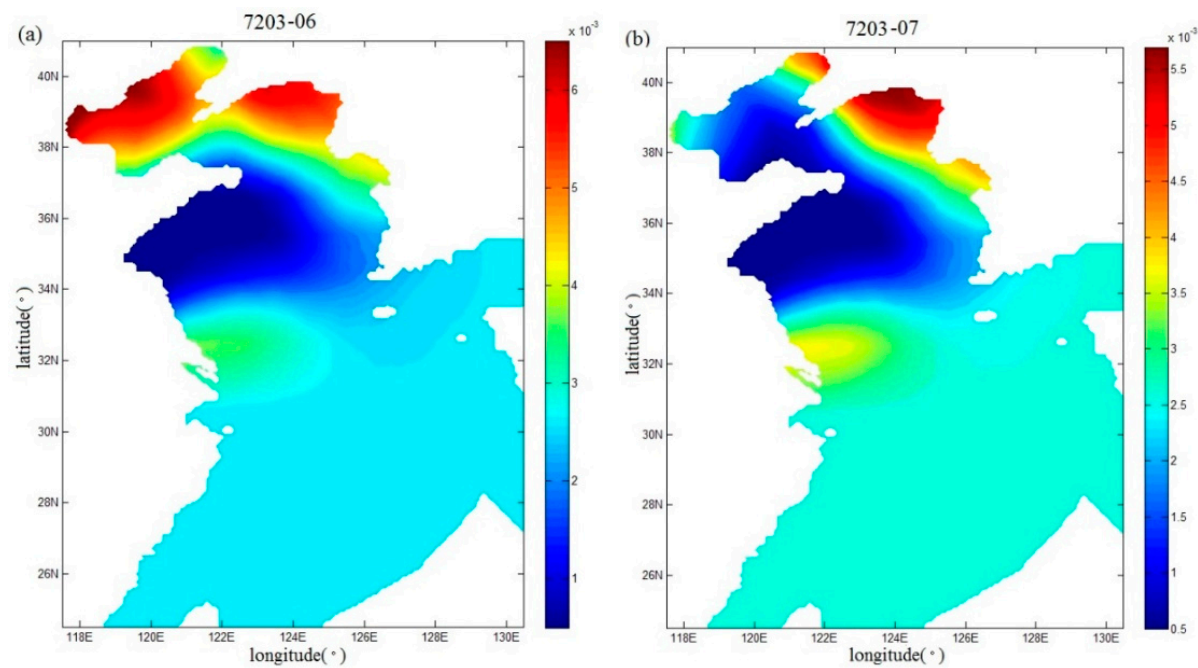

Figure 11. Spatial distributions $(\mathbf{a}, \mathbf{b})$ of the drag coefficient in the sixth and seventh periods in Case 5 during Typhoon 7203. 
(a)

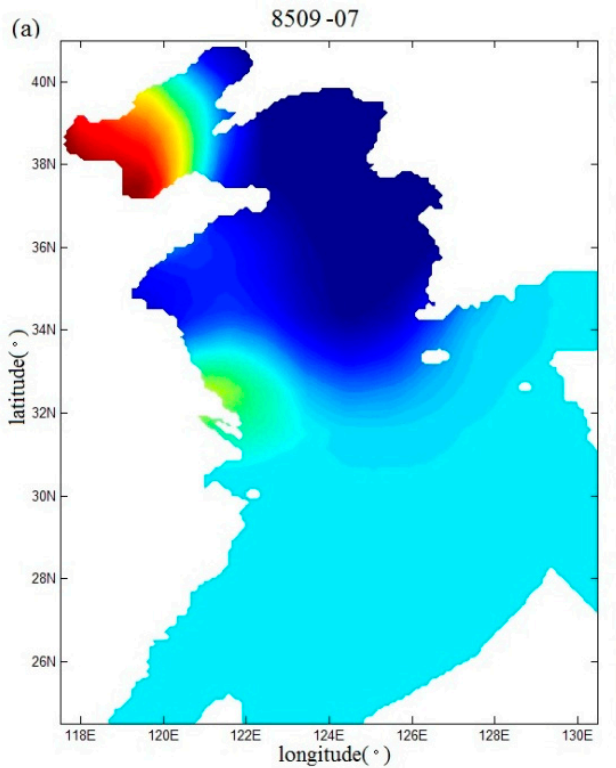

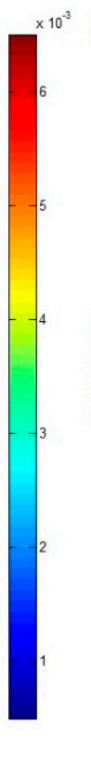

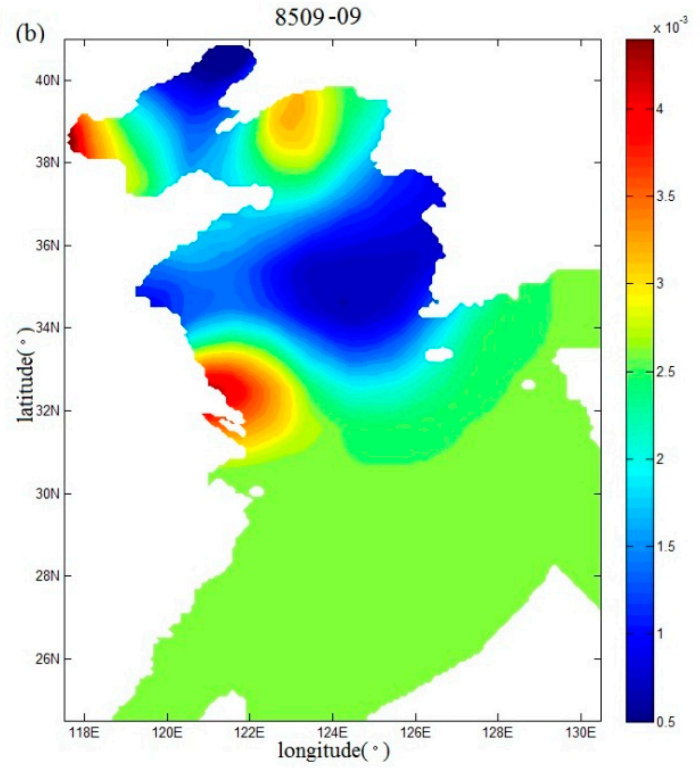

Figure 12. Spatial distributions $(\mathbf{a}, \mathbf{b})$ of the drag coefficient in the seventh and ninth periods in Case 5 during Typhoon 8509.

With the inverted drag coefficient in the sixth and seventh periods during Typhoon 7203, the simulated spatial distributions of storm surge elevation and wind field in the seventh and eighth periods are shown in Figure 9c,d. From Figure 9c,d, the winds mainly blow toward the land and push water toward the coast so as to raise the sea level in the Bohai Sea, but in the South Yellow Sea the negative storm surges dominate under the influence of offshore winds. Similarly, for Typhoon 8509, by using the inverted drag coefficient in the seventh and ninth periods, the simulated spatial distributions of storm surge elevation and wind field in the eighth and tenth periods are mapped in Figure 10c,d. From Figure 10c, d we can see that the negative storm surges mainly occur in the South Yellow Sea where the offshore wind plays a leading role.

\section{Conclusions}

By assimilating the observed water levels at tide stations during Typhoons 7203 and 8509 into a numerical assimilation model, the water levels in the Bohai Sea, Yellow Sea, and East China Sea were simulated. The drag coefficient in whole areas was inverted during the two Typhoons. The Tikhonov regularization technique with different regularization parameters were applied to the process of adjoint assimilation.

To study the impacts of different regularization parameters on the simulation results, five experiments, denoted by Cases $0-4$, were carried out with five regularization parameters $0,1,10$, 100, and 1000, respectively. The results showed that for Typhoon 7203, the mean RMS differences in C0-C4 were 15, 14, 14, 13, and $16 \mathrm{~cm}$, respectively. Among them, the mean value in C3 was the smallest. For Typhoon 8509, the mean RMS differences in C0-C4 were respectively 23, 19, 19, 19, and 19. Meanwhile, the storm surge elevations calculated with the regularization technique were compared with those obtained with the independent point method, and the result indicates that the former one performed better.

The result of Case 3 was used for further investigation. The spatial distributions of the drag coefficients in the sixth and seventh periods during Typhoon 7203 and those in the seventh and ninth periods during Typhoon 8509 were displayed. These results demonstrate that different typhoon trajectories can lead to the different drag coefficients, and the drag coefficient has more obvious variation in the coastal waters of the Bohai Sea and northern Yellow Sea. Finally, spatial distribution of storm surge elevation and wind field during the two Typhoons were shown. These results indicate 
that onshore winds push water toward the coast so as to increase the water elevation in the Bohai Sea and offshore winds can excite the negative storm surge in the South Yellow Sea.

Author Contributions: Conceptualization, J.X. and X.L.; methodology, Y.Z. and Q.L.; software, J.X.; formal analysis, Y.Z.; investigation, J.X.; writing—original draft preparation, J.X. and Y.Z.; writing-review and editing, J.X. and X.L.

Funding: This research was funded by the National Natural Science Foundation of China, grant number 41606006 and U1806214, the National Key Research and Development Plan of China, grant number 2016YFC1402705 and 2016YFC1402304.

Acknowledgments: The paper was supported by Qingdao University of Science and Technology and Ocean University of China.

Conflicts of Interest: The authors declare no conflict of interest.

\section{References}

1. You, S.H.; Seo, J.W. Storm surge prediction using an artificial neural network model and cluster analysis. Nat. Hazards 2009, 1, 97-114. [CrossRef]

2. Shaji, C.; Kar, S.K.; Vishal, T. Storm surge studies in the North Indian Ocean: A review. Indian J. Geo-Mar. Sci. 2014, 43, 125-147.

3. Muis, S.; Verlaan, M.; Winsemius, H.C.; Aerts, J.C.J.H.; Ward, P.J. A global reanalysis of storm surges and extreme sea levels. Nat. Commun. 2016, 7, 11969. [CrossRef]

4. Zhao, Y.B.; Liang, X.S. Cause and underlying dynamic processes of the mid-winter suppression in the North Pacific storm track. Sci. China Earth Sci. 2019, 162, 872-890. [CrossRef]

5. Lin, N.; Emanuel, K.; Oppenheimer, M.; Vanmarcke, E. Physically based assessment of hurricane surge threat under climate change. Nat. Clim. Chang. 2012, 2, 462-467. [CrossRef]

6. Liu, H.Q.; Zhang, K.Q.; Li, Y.P.; Xie, L.A. Numerical study of the sensitivity of mangroves in reducing storm surge and flooding to hurricane characteristics in southern Florida. Cont. Shelf Res. 2013, 64, 51-65. [CrossRef]

7. Haigh, I.D.; Wijeratne, E.M.S.; MacPherson, L.R.; Pattiaratchi, C.B.; Mason, M.S.; Crompton, R.P.; George, S. Estimating present day extreme water level exceedance probabilities around the coastline of Australia: Tides, extra-tropical storm surges and mean sea level. Clim. Dyn. 2014, 42, 121-138. [CrossRef]

8. Dong, S.; Gao, J.G.; Li, X.; Wei, Y.; Wang, L. A Storm Surge Intensity Classification Based on Extreme Water Level and Concomitant Wave Height. J. Ocean Univ. China 2015, 14, 237-244. [CrossRef]

9. Zhang, H.; Cheng, W.C.; Qiu, X.X.; Feng, X.B.; Gong, W.P. Tide-surge interaction along the east coast of the Leizhou Peninsula, South China Sea. Cont. Shelf Res. 2017, 142, 32-49. [CrossRef]

10. Olbert, A.I.; Nash, S.; Cunnane, C.; Hartnett, M. Tide-surge interactions and their effects on total sea levels in Irish coastal waters. Ocean Dyn. 2013, 63, 599-614. [CrossRef]

11. Zheng, J.H.; Wang, J.C.; Zhou, C.Y.; Zhao, H.J.; Sang, S. Numerical simulation of typhoon-induced storm surge along Jiangsu coast, Part II: Calculation of storm surge. Water Sci. Eng. 2017, 10, 8-16. [CrossRef]

12. Ridder, N.; De, V.H.; Drijfhout, S.; Henk, V.D.B.; Van, M.E.; De, V.H. Extreme storm surge modeling in the North Sea. Ocean Dyn. 2018, 68, 255-272. [CrossRef]

13. Lionello, P.; Sanna, A.; Elvini, E.; Mufato, R. A data assimilation procedure for operational prediction of storm surge in the northern Adriatic Sea. Cont. Shelf Res. 2006, 26, 539-553. [CrossRef]

14. Peng, S.Q.; Xie, L.A. Effect of determining initial conditions by four-dimensional variational data assimilation on storm surge forecasting. Ocean Model. 2006, 14, 1-18. [CrossRef]

15. Peng, S.Q.; Xie, L.A.; Pietrafesa, L.J. Correcting the errors in the initial conditions and wind stress in storm surge simulation using an adjoint optimal technique. Ocean Model. 2007, 18, 175-193. [CrossRef]

16. Yin, B.S.; Xu, Z.H.; Huang, Y.; Lin, X. Simulating a typhoon storm surge in the East Sea of China using a coupled model. Prog. Nat. Sci. 2009, 19, 65-71. [CrossRef]

17. Fan, L.L.; Liu, M.M.; Chen, H.B.; Lu, X.Q. Numerical study on the spatially varying drag coefficient in simulation of storm surges employing the adjoint method. Chin. J. Oceanol. Limnol. 2011, 29, 702-717. [CrossRef]

18. Li, Y.N.; Peng, S.Q.; Yan, J.; Xie, L.A. On improving storm surge forecasting using an adjoint optimal technique. Ocean Model. 2013, 72, 185-197. [CrossRef] 
19. Feng, J.L.; Jiang, W.S.; Bian, C.W. Numerieal Prediction of Storm Surge in the Qingdao Area Under the Impact of Climate Change. J. Ocean Univ. China 2014, 13, 539-551. [CrossRef]

20. Xu, J.L.; Zhang, Y.H.; Cao, A.Z.; Liu, Q.; Lv, X.Q. Effects of tide-surge interactions on storm surges along the coast of the Bohai Sea, Yellow Sea, and East China Sea. Sci. China Earth Sci. 2016, 59, 1308-1316. [CrossRef]

21. Tikhonov, A.N. Solution of incorrectly formulated problems and the regularization method. Sov. Math. Dokl. 1963, 5, 1035-1038.

22. Morozov, V.A. Methods for Solving Incorrectly Posed Problems; Springer: New York, NY, USA, 1984; p. 65.

23. Chen, H.B.; Cao, A.Z.; Zhang, J.C.; Miao, C.B.; Lv, X.Q. Estimation of spatially varying open boundary conditions for a numerical internal tidal model with adjoint method. Math. Comput. Simul. 2014, 97, 14-38. [CrossRef]

24. Chen, J.; Weisberg, R.H.; Liu, Y.; Zheng, L. The Tampa Bay Coastal Ocean Circulation Model performance for Hurricane Irma. MTS J. 2018, 52, 33-42. [CrossRef]

25. Jelesnianski, C.P. A numerical calculation of storm tides induced by a tropical storm impinging on a continental shelf. Mon. Weather Rev. 1965, 93, 343-358. [CrossRef]

26. He, Y.J.; Lu, X.Q.; Qiu, Z.F.; Zhao, J.P. Shallow water tidal constituents in the Bohai Sea and the Yellow Sea from a numerical adjoint model with TOPEX/POSEIDON altimeter data. Cont. Shelf Res. 2004, 24, 1521-1529. [CrossRef]

27. Liu, Y.; Weisberg, R.H. Momentum balance diagnoses for the West Florida Shelf. Cont. Shelf Res. 2005, 25, 2054-2074. [CrossRef]

(C) 2019 by the authors. Licensee MDPI, Basel, Switzerland. This article is an open access article distributed under the terms and conditions of the Creative Commons Attribution (CC BY) license (http://creativecommons.org/licenses/by/4.0/). 